\title{
Vergi Bilincini Etkileyen Demografik ve Siyasi Faktörler: Kırgızistan Örneği
}

Raziyahan ABDIYEVA, Department of Economics, Faculty of Economics and Administrative Sciences, Krygyz Turkish MANAS University, Kyrgyzstan; e-mail: razia.abdieva@manas.edu.kg

Tolkun CUMAKUNOVA, Department of Economics, Faculty of Economics and Administrative Sciences, Krygyz - Turkish MANAS University, Kyrgyzstan; e-mail: tolkuna@list.ru

\section{Demographic and Political Factors Affecting Tax Consciousness: Case of Kyrgyzstan}

\begin{abstract}
Taxes are the main financial resource of government. Performance of tax system depends on the willingness of taxpayers to pay taxes or tax morale. Tax consciousness means that taxpayer is aware about taxes that paid, knows what taxes are and how tax revenue is used. Tax consciousness is important in the forming of tax behavior and in the improving democracy by increasing public control on public finance. Transitional economies as Kyrgyzstan government needs more financial resources to implement economic and social reforms, to decrease poverty and achieve sustainable development. Nowadays government seeks ways to increase tax revenue. In this paper authors aim to analyze tax consciousness of taxpayers in Kyrgyzstan using the questionnaire conducted in 2013 in the the capital city of Kyrgyzstan in Bishkek. Demographic and political factors that affect tax consciousness will be analyzed with probit model.
\end{abstract}

\section{Keywords $\quad$ : Tax Conciousness, Probit Model, Kyrgyzstan.}

JEL Classification Codes : $\quad$ H26, H30.

\section{$\ddot{\mathbf{O} z}$}

Vergiler devletin temel gelir kaynağıdır. Vergi sisteminin etkinliği mükelleflerin kendi yükümlülüklerini ne kadar tam ve doğru yerine getirme isteklerine bağlıdır. Vergi bilinci mükelleflerin ödedikleri vergilerin farkına vardıklarını, bu vergilerin niçin ödenmesi gerektiği ve nasıl kullanıldığı hakkında bilgi sahibi olduklarını ifade etmektedir. Vergi bilinci ülkede vergi kültürünün oluşmasında ve kamu maliyesinin halk tarafindan denetlenmesi ve demokrasinin gelişmesi için de önemlidir. Kırgızistan gibi geçiş ekonomilerinin ekonomik ve sosyal reformları yürütmek, fakirliği azaltmak ve sürdürülebilir kalkınmaya ulaşmak için daha çok mali kaynaklara ihtiyacı vardır. Günümüzde Kırgızistan hükümeti vergi gelirlerini artırma yollarının arayışındadır. Bu çalışmada Kırgızistan'daki mükelleflerin vergi bilinci incelenmiştir. Kırgızistan'ın başkenti Bişkek'te 2013 yılında 400 kişiye yapılan anket sonuçlarına göre analiz edilmiştir. Makalede probit modeli uygulanarak vergi bilincini etkileyen demografik ve siyasal faktörler incelenmiştir.

Anahtar Sözcükler $\quad$ : Vergi Bilinci, Probit Modeli, Kırgızistan. 


\section{Giriş}

Günümüz dünya ülkelerinde kamu giderlerini karşılamak için en önemli kaynak vergi gelirleridir. Vergi, kamusal mal ve hizmetleri finanse etmek amacı ile devlet tarafindan hukuki zorunluluk altında, yasayla belirtilen kurallara göre karşılıksız alınan iktisadi değerdir.

Vergileme olgusunda vergileri ödeyen mükellefler ve vergileri tahsil eden devlet tarafı olduğuna göre, vergilemenin başarısı da bu iki tarafın davranışlarına bağlıdır. Demokratik devletlerde kamu görüşü ve bilgisi kamu yönetimi ve maliyesi üzerindeki etkisi ve önemi çok yüksektir. İyi bir vergi bilincinin oluşturulması kamu yönetiminin ve kamu gelirlerinin sağlıklı olmasına imkân sağlar (Buehler, 1940).

Özellikle modern vergi sisteminde beyan usulu kullanıldığından mükelleflerin vergileri algılamaları, vergi bilinçleri ve vergiye karşı tutum ve davranışları vergi sistemini önemli derecede etkileyebilmektedir. Böylece, etkin vergi sistemi vergi yükümlülüklerini doğru ve tam anlayan ve yerine getiren mükelleflerin olmasını talep etmektedir.

Çalışmada Kırgızistan'da mükelleflerin vergiyi nasıl algıladıkları ve vergi bilincini incelemek amaçlanmıştır. Giriş bölümünü izleyen ikinci bölümde vergi bilinci kavramı ve vergi bilincini etkileyen faktörler araştırılmıştır. Üçüncü bölümde ise veri ve betimsel istatistikler sunulmuştur. Dördüncü bölümde model ve ampirik sonuçlar ve beşinci bölümde de sonuç ve değerlendirme sunulmuştur.

\section{Vergi Bilinci Kavramı}

Literatürde vergi bilinci üzerinde uzlaşmış bir tanım mevcut değildir. Dornstein'e (1987) göre vergi bilinci, verginin farkında olunması olarak tanımlanııı̧sa; Torgler'e (2005) göre vergi bilinci mükellefin vergiyi ödeme konusundaki içsel motivasyonu; Edizdoğan, Çetinkaya ve Gümüş'e (2010) göre ise bireylerin gelirlerinden veya servetlerinden devletin yerine getirmekte yükümlü olduğu kamu hizmetlerinin gerçekleştirilmesi için kanunda belirtilen usul, esas ve oranlara göre katkıda bulunmaları gerektiğini fark etme yeteneği olarak; Savaşan ve Odabaş ise (2005) bireyin kullandıği kamusal mal ve hizmet ile ödediği verginin ilişkilendirilmesi; Demir (2016) vergi bilincini vergi ile ilgili bireylerin sahip oldukları farkındalık düzeyi olarak; Akdoğan (2005) ise kamu hizmetlerinin gerçekleştirilmesi için vergiyi önemseyen bireyler vergi ile ilgili ödevlerini yerine getirmedeki istekliliklerinin düzeyi olarak tanımlamaktadırlar.

Şener (1997) vergi bilincinin sadece vergiyi ödeme bilinci olarak algılanmaması gerektiğini, bunun yanı sıra mükelleflerin ödediği vergilerin nerelere harcandığının denetimini ifade eden bir kavram olarak da değerlendirilmesi gerektiğini belirtmektedir. Edizdoğan v.d. (2010) Şener'in düşüncelerine katılarak vergi bilincini mükelleflerin ödediği vergilerin nasıl harcandığını bilmeleri olarak da açıklamaktadırlar. Yeşilyurt (2015) vergi bilinci tanımlamasında verginin gerekliliğine inanma, bunun kamu hizmetlerinin sürdürülmesi için önemli faktör olduğunu kavrama ve devletin yapmış olduğu harcamaları 
vatandaşlar ile paylaşma durumu olarak belirtmektedir. Bunun yanı sıra Kalafat (2016) ise mükelleflerin vergilemede var olan ilgileri ve motivasyonları, vergi konusunda yükümlü olduğu ödevleri kanunlara göre yerine getirmede gösterdikleri gayretleri ve vergi idaresine karşı olan tutum biçimleri olarak tanımlamaktadır.

$\mathrm{Bu}$ tanımlardan vergi bilinci ilk önce vatandaşların vergi ödediklerinden farkında olmalarını, bundan sonra bu vergileri niçin ödediklerini (kamusal mal ve hizmetlerin finansmanı için olduğunu) anladıklarını ve bu bilgilere sahip olduktan sonra ödedikleri vergi gelirlerinin nasıl harcandığını izlemeleri ve faydalandıkları kamusal hizmet ve mallarla ilişkilendirebilmeleri olduğu ortaya çıkmaktadır. Vatandaş bu bilgilere sahip olduktan sonra vergiye karşı olumlu veya olumsuz tutum ve davranışı seçecektir veya verginin ödenmesi gerektiğine dair olumlu veya olumsuz görüş oluşacaktır. Böylece, genel olarak vergi bilinci vatandaşların ödediği verginin farkında olmaları, bu vergilerin niçin ödendiğini bilmeleri, vergi gelirlerinin nasıl harcandı̆̆ına ilgi göstermeleri ve sonuçta verginin gerek olup olmadığı ile ilgili görüşler şeklinde tanımlanabilir.

Vergi bilinci mükelleflerin vergileri nasıl algıladıklarını, vergi ile ilgili tutum ve davranışlarını ve son olarak vergi kültürünün düzeyini etkileyebilmektedir. Diğer bir değişle, vergi bilinci vergi kültürünün ilk aşaması sayılabilir. Demek ki, mükellefin vergi yükümlülüklerini yerine getirmesi ile ilgili aldığı kararları ve yaptığı davranışları onun vergi bilinci ve vergileri algılamalarına bağlıdır denilebilir. Toplumda vergi bilinci ne kadar arttırılsa, devletin gücü ve devletin sağlayacağı imkanlar (daha iyi eğitim, daha iyi sağlık hizmeti gibi) da o oranda arttırılmış olacaktır (Taytak, 2010).

\section{Vergi Bilinci Konusunda Literatürde Yapılmış Bazı Çalışmalar}

Vergilemede kişilerin kendilerinin gönüllü olarak vergi ödemeleri ya da ödememeleri için vergi bilinç düzeyleri büyük önem taşımaktadır. Mükellefin vergiyi ödemeyi ya da ödemememesini her türlü faktörler etkilemektedir. Bu yüzden vergi bilinci ile birlikte vergi bilincini etkileyen faktörler de birçok çalışmalarda ele alınmıştır.

Zorlu (2012) tarafından yapılan çalışmada Türkiye'de ilk öğretim 9-15 yaş grubu arasındaki 3-8.sınıf öğrencilerinin vergi kavramından ne anladıklarını belirlemek ve sahip oldukları vergi bilinçlerini ölçmeyi amaçlayan çalışma yapılmıştır. Araştırmada 500 ilköğretim öğrencisinden anket alınmış ve vergi bilincinin, öğrencilerin sosyo-demografik özelliklerine göre farklılık gösterme durumları bu çalışmada incelenmiştir. Çalışma sonucunda öğrencilerin vergi bilinci düzeyleri, anne veya baba öğrenim durumuna, cinsiyetlerine, baba mesleğine ve ailelerin ortalama aylık gelir durumlarına göre anlamlı farklılık göstermediği; yaşlarına, anne mesleğine, okudukları sınıflara göre ise anlamlı farklılık gösterdiği ortaya konulmuştur.

Taytak (2010) tarafindan yapılan çalışmada ilköğretim II. kademe öğrencilerinin vergi bilincini tespit etmek ve vergi bilincinin oluşmasında etkili olan faktörlerin neler olduğu konusu incelenmiştir. Taytak vergi bilinci ve kişilerin vergiye karşı gösterdikleri uyumun çok çeşitli faktörlerden (yaş, cinsiyet, gelir durumu, eğitim seviyesi, kişinin ahlaki 
hali, mevzuat vb.) etkilendiğini ifade etmekte. Çalışmada özellikle eğitim düzeyi ile vergi uyumu arasındaki ilişki incelenmiş olup 6,7 , ve 8 'inci sınıfların vergiye uyumu noktasında farklı yansımaların ortaya çıktığını ve eğitim düzeyinin vergiye uyumun sağlanmasında önemli bir faktör olduğunu açıklamaktadır.

Yeşilyurt (2015) yapmış olduğu çalışmada vergiye yönelik tutum ve davranışları önemli bir şekilde etkileyen vergi ahlakının oluşmasında vergi bilincinin etkisini incelemiştir ve Zonguldak Bülent Ecevit Üniversitesi Maliye Bölümü ve İlahiyat Fakültesi öğrencilerine anket uygulaması yapılmıştır. Ankete 473 öğrenci katılmıştır. Çalışmada amaç ekonomik konuda daha çok eğitim alan maliye bölümü öğrencileri ile dini, ahlaki konularda daha ağırlıklı eğitim alan ilahiyat bölümü öğrencilerinin vergi bilinci ve vergi ahlakı düzeylerini kıyaslamaktır. Çalışma sonucunda ilahiyat bölümü öğrencilerinin vergi bilinci ve vergi ahlakına yönelik ifadelere maliye bölümü öğrencilerine göre daha fazla katıldıkları sonucunu elde etmiştir.

Cansız (2006) tarafından yapılan çalışmada vergilerin vatandaşlar tarafından nasıl algılandığı, vergi sistemine nasıl bakıldığı, mükelleflerin vergi ödemesini etkileyen faktörlerin neler olduğu, vergi kaçakçılığına bakışı ve vergi bilincini olumlu anlamalarına ilişkin soruların yanıtlanması araştırılmış ve Afyonkarahisar ili ve ilçelerinden 816 insana anket uygulanmıştır. Sonuçta vatandaşların hükümet ve vergi idaresinden birtakım beklentileri olduğunu, ama verginin bir vatandaşlık görevi olduğu düşüncesinin kabul edildiğini ifade etmiştir. Bununla birlikte vergi bilincini artırabilmek için yaşamın her aşamasında vergi konusunda eğitimin verilmesi gerektiği sonucuna gidilmiştir.

Demir ve Ciğerci (2016) tarafindan yapılan çalışmada ise vergi bilincinin oluşumunda eğitimin rolü tespit edilmeye çaba gösterilmiştir. İlk olarak 3. ve 4. sınıf öğrencilerinin vergiyle ilgili bilgileri, vergiyi nasıl algıladıkları daha doğrusu vergi bilinç düzeyleri tespit edilmiştir. Verginin doğru algılanmadığı, bazı yanılgılar olduğu ortaya çıkmıştır. Fakat aynı öğrencilere gerekli eğitimlerin verilmesi ile birlikte vergi bilinç düzeylerinde belirgin bir şekilde pozitif değişikliklerin olduğu görülmüştür.

Gürler Hazman (2009)'ın çalışmasında ise vergi bilincini etkileyen dışsal karakterli etkenleri ortaya koymaya yönelmiştir. Elde edilen sonuçlara göre vergi bilincinin dişsal faktörleri olarak vergi yönetiminden ve sisteminden kaynaklanan faktörler; ekonomik konjonktürden kaynaklanan faktörler ve siyasal yapıdan kaynaklanan faktörler sıralanmıştır.

İzgi ve Saruç (2011) tarafından yapılan çalışmada sosyo-kültürel faktörlerin bireylerin vergi ödemedeki etkisi açıklanmaya çalışılmıştır. Bu bağlamda Sakarya Üniversitesi'nde kolayda örnekleme yöntemine göre seçilmiş 1351 üniversite öğrencisine anket uygulanmıştır. Analiz sonucunda vergi ahlakı ile devlete bağlılık, vatandaşlık bilinci ve din faktörü arasında anlamlı bir fark olduğunu; vergi ahlakı ile iktidar partiyi kabul düzeyi arasında ise anlamlı bir farkın olmadı̆̆

Korlu, Çetinkaya ve Gerçek (2016) tarafından yapılan araştırmada ise yerel vergi bilincini belirleyen sosyal ve psikolojik faktörler olarak; adalet ve eşitlik, din ve ahlak, 
katılımcılık ve yerelleşme, kültür, idareye bakış ve siyasi anlayış ele alınmıştır. Çalışmada Bursa ilinin on ilçesinde 680 kişiye anket uygulanmış. Yapılan Faktör Analizi sonucunda vatandaşlar açısından yerel vergi bilincini belirleyen en önemli faktör adalet ve eşitlik, ikinci önemli faktör din ve ahlak olduğu ortaya çıkmıştır.

Durmuş (2015) tarafından yapılan çalışmada üniversite öğrencilerinin vergi bilinç düzeylerinin, fiş fatura duyarlılıkları üzerine olan etkisini incelemek hedeflenmiştir. Araştırmada Aksaray Üniversitesi İIBF, Mühendislik Fakültesi, Fen Edebiyat Fakültesi, Eğitim Fakültesi ve BESYO toplam 292 öğrenciye anket uygulanmış, bunların arasından Maliye-Vergi dersi alanlar da değerlendirilmiştir. Çalışma sonucu olarak vergi bilinci yükselmesi vergi gelirlerini toplama sırasında yapılan maliyetler için belge istenmesi ile kayıt dışı ekonominin önlenmesine katkı sağlanabilir. Böylece öğrencilerin vergi dersi almaları vergi bilinçlerini, dolaylı olarak da kayıt dışı ekonomiyle mücadele anlamında da katkı sağlayacağı düşünüldüğü ifade edilmektedir.

Özdemir ve Ayvalı (2007) tarafından yapılan çalışmanın amacı ise vergi bilincine sahip bireylerin fiş veya fatura alma duyarlılığını etkileyen faktörlerin belirlenmesidir. Çalışmada 113 maliye öğretim elemanına anket uygulanmış ve sonucunda fiş-fatura alma sıklığının; evli, yüksek gelirli olmak ve kamu hizmetlerinden faydalanmak, vergi bilinci, ahlakı ve sorumluluğuna sahip olmak ve teşvik almak ile doğru orantılı; aşırı vergi yükü ve adaletsizliğe tabi olmak ile ters orantılı bir ilişki içinde olduğu ortaya çıkmıştır.

Ömürbek, Çiçek ve Çiçek (2007) tarafından yapılan çalışmada Süleyman Demirel Üniversitesi İktisadi ve İdari Bilimler Fakültesi 4.sınıf 316 öğrenciden anket alınmıştır. Araştırmanın amacı öğrencilerin vergi bilinç düzeyini ölçmek ve değerlendirmektir. Sonucunda da Türkiye'de potansiyel vergi mükellefi durumundaki üniversite öğrencilerine göre vergi ödemeyi/ödememeyi belirleyen en önemli faktörler sırasıyla ödenilen vergilerin çok açık ve net olarak nerelerde kullandığının bilinmesi, daha şeffaf ve hesap verebilir devlet yönetimi, adil bir vergi yükü dağılımı olarak açıklamıştır.

\section{Kırgızistan'da Vergi Bilincinin Gelişimi}

Kırgızistan 1991 yılında SSCB'nin dağılması ile kendi bağımsızlığına kavuşan geçiş ekonomili bir ülkedir. SSCB döneminde işletmelerden sadece iki çeşit vergi: satış vergisi (turnover tax) ve kar üzerinden kesintiler vardı. Halktan alınan vergilerin önemli kısmı iptal edilerek sadece bazıları birleştirilerek yürürlükte kalmıştır. Tüm üretim ve ticaret şirketlerinin karları, fonların oluşturulması için ayrılan paylar dışında, devlet bütçesine alınıyordu. Böylece, kamu gelirleri vergiler ile değil devlet monopolü altında üretilen gayri safi yurt içi hasıladan direkt kesintilerden oluşmaktaydı. Sonuç olarak vergi ve vergilemenin bütçe için anlamı önemli derecede kaybolmuştu (Parıgina, 2016).

II. Dünya Savaşı döneminde işletmelerden aynı vergiler alınmaya devam edilmiştir. Fakat kaynak sıkıntısı nedeni ile 21 Kasım 1941 ve 8 Temmuz 1944 Tarihlerinde halktan bekarlar vergisi, boşanmış ve az kişili ailelerden vergi, askeri vergi, sığır üzerinden vergi, avcılık ve ticari amaçla kullanacak köpekler üzerinden vergi alınmaya başlamıştır. Savaş 
sonrası ise vergiler yavaş yavaş vergi dışı gelirlerle değiştirilmiştir (Parıgina, 2016). Vatandaşlardan alınan vergiler SSCB genel bütçe gelirlerinin sadece \%7'sini oluşturmuştur (R1saliyeva, 2008: 117). Böylece SSCB döneminde vergiler kendi fonksiyonlarını yitirdiklerinden dolayı vatandaşlar vergilerin ödendiğinin farkına varamamışlar, vergi ödemenin gerekliliğini hissedememişler, diğer bir değişle, vatandaşların vergi bilinci oluşmamıştır.

Kırgız Cumhuriyeti ise 1992 y1lından itibaren piyasa ekonomisine uygun bir vergi sistemi oluşturmaya başlamıştır. Vergi idaresinin piyasa ekonomisine uygun bir vergi sistemini yönetme tecrübesinin yok olması ve halkın da vergi bilincinin olmaması etkin bir vergi sisteminin oluşmasında ciddi bir sorun yaratmıştır. Kayıt dışı ekonomi 2000 yılında GSYİH'nın \%46,3'üne, 2008'de ise \%42,3'üne ulaşmıştır (Karatalov, 2010: 28). Fakat Yakışığın (2006) hesaplamalarına göre ise 1994 yılında kayıt dışı ekonomi GSYİH'nın \% 76, 2005 'te ise \%92'sine yükselmiştir. 2012'de ise bu oran \%39'a inmiştir (Esenalieva, 2012). Kurumlar vergisi oran $\% 10$ ve gelir vergisinin de oran $1 \% 10$ olup bu bölge ulkelerindeki en düşük oranlardan olmasina rağmen kayıt dışı ekonominin payı yüksektir. Vatandaşların vergi bilincini ve vergi kültürünü geliştirmek güncel sorunlardan olmaktadır.

\section{Veri ve Betimsel İstatistikler}

Çalışmada Kırgızistan'ın başkenti olan Bişkek şehrinde 2013 yılında 400 kişiden toplanan anket verileri kullanılmıştır. Katılımcıların \%39,3'ü (157 kişi) erkek, \%60,7'si (243 kişi) bayandır; yüzde 66,3\%’̈̈ evli ve \%32,3’ü bekardır.

Yaşına göre dağılımına bakıldığında \%39'u 16-29 yaş arası, \%42,8'i 30-49 yaş arası, \%16,8'i 50-69 yaş arası ve \%1,2'si de 70 yaştan büyük olanlardır. Eğitim durumuna göre katılımcıların \%8,5'i ortaokul mezunu, \%18,8'i meslek yüksekokulu mezunu, \%73,2'si üniversite mezunu ve $\% 4,8$ 'i de yüksek lisans ve daha üst düzeyde eğitimli olanlardır. Aylık ortalama gelirinin seviyesine baktığımızda katılımcıların \%11,5'inin ortalama aylık geliri 5000 soma kadar, \%1,5'inin ise 5000-10 000 som arası, \%23'ünün geliri 10 001-15 000 som arası, \%19,5'inin 15000 - 25000 som arası ve \%11,5'inin de aylık ortalama geliri 25000 somdan yukarı olduğu açıklanmıştır.

\section{Ampirik Sonuçlar}

Vergi bilincini etkileyen demografik ve siyasi faktörler probit modeli ile incelenmiştir. Modelde vergi bilincini temsil eden bağımlı değişken olarak ankette verilen aşağıdaki soru alınmıştır:

'Sizce vergiler gerekli midir?'

\subsection{Vergi Bilincini Etkileyen Demografik Faktörlerle İlgili Model ve Sonuçları}

Aşağıdaki tabloda vergi bilincini etkileyen demografik faktörlerle ilgili modelde yer alan bağımsız değişkenlerin açıklamaları verilmiştir. 
Tablo: 1

Vergi Bilincini Etkileyen Demografik Faktörlerle İlgili Modelde Yer Alan Bağımsız Değișkenler

\begin{tabular}{|c|c|}
\hline Değişkenler & Açılama \\
\hline Cinsiyet & Ĕ̆er erkek ise 1, aksi halde 0. \\
\hline Yaş & Ĕger yaşı $50-69$ yaş arası ise 1, aks ihalde 0. \\
\hline Eğitim Seviyesi & Eğer üniversite mezunu ise 1, aksi halde 0. \\
\hline Geliri & Eğer aylık ortalama geliri 25000 som ve fazla ise 1 , aksi halde 0 \\
\hline
\end{tabular}

Tablo: 2

Probit Modelinin Sonuçları

\begin{tabular}{|c|c|c|}
\hline Değişkenler & Katsayı & Marjinal Etki \\
\hline Cinsiyet & $0.3169^{* *}$ & $0.0679^{* * *}$ \\
\hline Yaş & $0.3814^{* *}$ & $0.0904^{* * *}$ \\
\hline Eğitim Seviyesi & $-0.4362^{* * *}$ & $-0.1006^{* * *}$ \\
\hline Geliri & $-1.0417^{* *}$ & $-0.1315^{* * *}$ \\
\hline
\end{tabular}

LR chi2 (4) $=22.16$ (0.000) Pseudo R2 $=0.0669 \quad$ Log likelihood $=-154.49685$

Marjinal etki Vergi Bilinci değişkeninin 0 ve 1 arasındaki değişimine gore hesaplanmışıtır.

Not: *, **ve ***\%10,\%5 ve \%1 düzeyinde anlamlllı derecesini göstermektedir.

Probit modelinde elde edilen katsayılar direkt yorumlanamamaktadır. Bu katsayıları yorumlayabilmek için marjinal etkileri hesaplanmıştır. Model sonuçlarına gore ankete katılanlar arasından erkekler bayanlara göre \%6,8 oranında daha çok verginin gerek olduğunu düşünmektedirler. Model sonuçları yaşın da olumlu etkisi olduğunu göstermiştir. Diğer bir değişle, 50-69 yaş arasındaki mükellefler diğerlerine göre \%9'a daha çok verginin gerekli olduğunu düşünmektedirler.

Üniversite mezunu olanların vergi bilinci diğer eğitim seviyelerindeki katılımcılara nazaran $\% 10$ oranında düşük olduğu tespit edilmiştir. Aslında eğitim seviyesinin vergi bilinci üzerinde pozitif etkisinin olması beklenir. Fakat Kırgızistan örneğinde üniversite eğitimine sahip katılımcılar diğer gruplara göre vergilerin gerekli olduğuna daha az inanmaktadırlar. Bunun nedeni ülkedeki yolsuzluk ve kayıt dışı ekonominin yüksek olduğu, bütçe saydamlığının düşük ve kamu hizmetlerinin yetersizliği ve kalitesinin düşük olduğu olabilir. Üniversite eğitimi olanlar bu durumlarla ilgili bilgilere sahip olduğundan dolayı vergilerin adaletli karşılığının olmadığının farkına vararak vergileri daha az önemsemekte olabilirler.

Kırgızistan'da gelir ile vergi bilinci arasında da negatif bir ilişkinin olduğu tahmin edilmiştir. Model sonuçları gelir düzeyi en yüksek olan katılımcıların vergi bilinci veya ortalama geliri 25001 somdan yukarı olan mükelleflerin vergi bilinci diğer gelir gruplarına nazaran \%13 oranında düşük olduğu görülmektedir. Diğer bir değişle, geliri en yüksek olan gruptakiler vergilerin daha az gerekli olduğunu düşünmektedirler.

\subsection{Vergi Bilincini Etkileyen Siyasi Faktörlerle İlgili Model ve Sonuçları}

Aşağıdaki tabloda vergi bilincini etkileyen siyasi faktörlerle ilgili modelde yer alan bağımsız değiş̧kenlerin açıklamaları verilmiştir. 
Tablo: 3

\section{Vergi Bilincini Etkileyen Siyasi Faktörlerle İlgili Modelde Yer Alan Bağımsız}

Değişkenler

\begin{tabular}{|l|l|}
\hline Değişkenler & Açıklama \\
\hline Vergi sistemi hakkında bilgisi & Eğer vergi sistemi hakkında tam bilgiye sahipse 1, aksi halde 0. \\
\hline Vergi sisteminin adaletliliği & Eğer vergi sistemini adaletli sayıorise 1, aksi halde 0. \\
\hline Vergi Mevzuatı & Eğer vergi mevzuatı zor ve karmaşık ise 1, aksi halde 0. \\
\hline Devlete Olan GüveninYüksek Olması & Eğer devlete olan güveni yüksek ise 1, devlete olan güveni orta ise 0 \\
\hline Devlete Olan Güvenin Düşük Olması & Eğer devlete olan güveni düşük ise 1, devlete olan güveni orta ise 0 \\
\hline
\end{tabular}

Tablo: 4

\section{Probit Modelinin Sonuçları}

\begin{tabular}{|l|l|l|}
\hline Değişkenler & Katsay1 & Marjinal Etki \\
\hline Vergi sistemi hakkında bilgisi & $0.6515^{* *}$ & $0.1705^{* *}$ \\
\hline Vergi sisteminin adaletliliği & $1.2549^{* * *}$ & $0.4031^{* * *}$ \\
\hline Vergi Mevzuat1 & $-0.5960^{*}$ & $-0.0904^{* * *}$ \\
\hline Devlete Olan GüveninYüksek Olması & $0.9564^{* * *}$ & $0.2864^{* *}$ \\
\hline Devlete Olan Güvenin Düşük Olmas1 & $-0.7936^{* * *}$ & $-0.1203^{* * *}$ \\
\hline
\end{tabular}

LR chi2 (5) = 37.97 (0.000) Pseudo R2 $=0.1147 \quad$ Log likelihood $=-146.59065$

Marjinal etki Vergi Bilinci değişkeninin 0 ve 1 arasındaki değişimine gore hesaplanmuştır.

Not: *,**ve***\%10,\%5 ve\%1 düzeyinde anlamlllık derecesini göstermektedir.

Vergi bilincini etkileyen siyasi faktörlerle ilgili probit modeli sonuçlarına gore vergi sistemi hakkında tam bir bilgiye sahip olanlar diğerlerine göre vergileri \%17 oranında daha çok gerekli olarak saymaktadırlar. Özellikle vergi sistemini adaletli sayanların vergi bilinci bu görüşte olmayan diğer gruptaki katılımcılara göre \%40 oranında daha yüksektir. Devlete olan güven değişkeni incelenirken devlete olan güveni orta olan grup referans grubu olarak alınmıştır. Böylece, devlete güveni yüksek olan katılımcılar devlete olan güveni orta olan gruba göre vergileri \%29 oranında daha çok gerekli bir unsur olarak kabul etmektedirler. Devlete olan güveni düşük olanların vergi bilinci ise devlete olan güveni orta olanlara göre $\% 12$ oranında daha düşük olduğu tespit edilmiştir.

Vergi mevzuatını zor ve karmaşık olarak sayanların ise vergi bilinci diğerlerine göre $\% 9$ oranında daha düşüktür.

\section{Sonuç ve Değerlendirme}

Vergi bilinci mükelleflerin vergi yükümlülüklerini tam ve doğru bir şekilde gönüllü olarak yerine getirmelerini etkileyen önemli etkenlerden biridir. Vergi bilincinin yüksek olması devletin vergi yönetimi ile ilgili harcamalarını azaltarak kamu gelirlerinin sürekliliğini ve yeterliliğini sağlamaktadır.

Çalışmada piyasa ekonomisine geçiş sürecinde olan Kırgızistan'da vergi bilincini etkileyen demografik ve siyasi faktörler probit modeli ile incelenmiştir. Ampirik sonuçlara göre erkeklerin vergi bilinci bayanlara göre daha yüksektir. Yaş vergi bilincini pozitif yönde etkilemekte iken, gelir vergi bilincini negatif yönde etkilemektedir. Eğitim seviyesinin vergi bilincini olumlu etkilemesi beklenirken, araştırmanın sonuçları gelir seviyesi en yüksek 
olanlar vergiyi diğer gruptakilere göre \%10 oranında daha az gerekli bulmaktadırlar. Bu ilginç sonucun nedeni ülkede kayıt dışı ekonomi ve yolsuzluk seviyesinin yüksek olduğu ve kamu hizmetlerinin kalitesinin düşük olduğu bir durumda üniversite eğitimı alanların verginin adaletli bir karşılığının olmadığının farkına vararak vergiyi daha az gerekli bulmaları olarak tahmin edilebilir. Bunun nedenleri ayrı araştırmada ve sadece üniversite eğitimi alan katılımcıları kapsayacak şekilde inceleme konusu yapılabilir.

Vergi bilincini etkileyen en önemli faktörlerin siyasi faktörler olduğunu ampirik sonuçlar göstermektedir. Vergi sistemi hakkında tam bilgiye sahip olanlar vergilerin \%17 oranında daha çok gerekli olduğunu kabul etmekte iken, vergi mevzuatını zor ve karmaşık bulanlar vergilerin $\% 9$ oranında daha az gerekli olduğunu düşünmektedirler.

Vergi sisteminin adaletli olduğunu düşünenlerin vergi bilinci \%40 oranında daha yüksektir. Devlete olan güveni yüksek olanların vergi bilinci \%28 daha yüksek iken devlete olan güveni düşük olanların vergi bilinci de $\% 12$ daha düşüktür.

$\mathrm{Bu}$ sonuçlar çerçevesinde Kırgızistan'da vergi bilincinin artırılması için vergi sisteminin adaletliliğinin artırılması ve kayıt dışı ekonominin azaltılması ile ilgili çalışmalar yapılmalıdır. Bununla birlikte vatandaşların devlete olan güveninin artırılması gerekir. Bunun için yolsuzluğun azaltılması, kamu hizmetlerinin kalitesinin yükseltilmesi ve bütçe saydamlığının artırılması gerekmektedir. Son olarak vergi mevzuatının karmaşık olduğu kanaatini azaltmak için vergi mevzuatında sadeleştirmeler yapılarak dili basitleştirilebilir ve vergi idaresine yorumlama alanı bırakılabilir. Vergiler hakkında halkın geniş bir şekilde bilgilendirilmesi gerekmektedir. Özellikle okuldan başlayarak gençlerin bilgilendirilmesi vergi bilinci üzerinde olumlu etkide bulunacaktır.

\section{Kaynaklar}

Akdoğan, A. (2005), Kamu Maliyesi, 9. Bask1, Gazi Kitabevi, Ankara.

Cansız, H. (2006), "Vergi Mükelleflerinin Vergiyi Algılama Hakkındaki Görüşleri: Afyonkarahisar İli Örneği", Afyon Kocatepe Üniversitesi İIBF Dergisi, 8(2), 115-138.

Demir, C. \& İ. Ciğerci (2016), "Vergi Bilincinin Oluşumunda Eğitimin Rolü: İlköğretim Öğrencileriyle Ampirik Bir Çalışma”, Celal Bayar Üniversitesi İ̈BF, Yönetim ve Ekonomi Dergisi, 23(1), 127-143.

Dornstein, M. (1987), “Taxes: Attitudes and Perceptions and Their Social Bases”, Journal of Economic Psychology, 8, 55-76.

Durmuş, M.A. (2015), "The Level of Consciousness for College Students Receipt of Tax-Invoice with Sensitivity Relationship: A Study at Aksaray University", Journal of Social and Humanities Sciences Research, 5(1), 29-47.

Edizdoğan N. \& Ö. Çetinkaya \& E. Gümüş (2010), Kamu Maliyesi, Ekin Basım Yayın, Bursa.

Egeli, H. \& F. Diril (2014), "Vergi Bilincinin Oluşumunda Bilişim Teknolojilerinin Rolü: İzmir İli İçin Bir Uygulama", Sosyoekonomi, 22(22), 34-56.

Esenalieva, D. (2012), Uroven tenevoy ekonomiki Kırgızstana sostovlyaet 39\% VVP - issledovaniye, <http://rus.kg/news_rus/economy_rus/8699-uroven-tenevoy-ekonomiki-kyrgyzstanasostavlyaet-39-vvp-issledovanie.html>, 29.09.2016. 
Hazman, G.G. (2009), "Vergi Bilincini Etkileyen Muhtemel Dışsal Etkenlerin Lojistik Regresyon Analizi Ile Tespiti", Akademik Incelemeler Dergisi, 4(1), 53-54.

İzgi, K. \& N.T. Saruç (2011), "Sosyo-Kültürel Faktörlerin Vergi Ahlakı Üzerindeki Etkisi: Üniversite Öğrencileri ile Yapılan Anket Çalışması”, Ekonomi Bilimleri Dergisi, 3(2), 133-142.

Kalafat, T. (2016), Mali Sosyoloji Açısından Vergi Bilinci ve Vergi Ahlakı, <http://www.vergivizyon.net/mali-sosyoloji-acisindan-vergi-bilinci-ve-vergi-ahlaki/>, 20.05.2016.

Karatalov, O. (2010), Налоги и «теневая» экономика. Сборник материалов второй научнопрактической конференции, по вопросам применения Налогового кодекса Кыргызской Республики. КРСУ. USAID. Бишкек, ОсОО Издательский дом «Салам».

Korlu, R.K. \& Ö. Çetinkaya \& A. Gerçek (2016), "Yerel Vergi Bilincinin Faktör Analizi ile Değerlendirilmesi: Bursa Örneği”, Yönetim Bilimleri Dergisi, 14(28), 443-463.

Ömürbek, N. \& H.G. Çiçek \& S. Çiçek (2007), "Vergi Bilinci Üzerine Bir İnceleme: Üniversite Öğrencileri Üzerinde Yapılan Anketin Bulguları”, Maliye Dergisi, 153, 102-122.

Özdemir, A.R. \& H. Ayvalı (2007), "Vergi Bilincine Sahip Bireylerin Fiş veya Fatura Alma Duyarlılığını Etkileyen Faktörler", Maliye Dergisi, 153, 51-73.

Parıgina, V.A. (2016), Kratkaya istoriya nalogov i nalogooblojeniya $v$ Rossii, <http://www.elitarium.ru/nalogi-nalogooblozhenie-ussr-rossija-poshlina-bjudzhetistorija/>, 28.09.2016.

Risaliyeva, M.Ş. (2008), Налоговая система Кыргызской Республики: История, современное состояние, перспективы. «Абыкеев А.Э», Бишкек.

Savaşan, F. \& H. Odabaş (2005), "Türkiye'de Vergi Kayıp ve Kaçaklarının Nedenleri Üzerine Ampirik Bir Çalışma”, Selçuk Üniversitesi IIIBF, Sosyal ve Ekonomik Araştırmalar Dergisi, 10, 1-28.

Şener, A. (1997), "Verginin Önemi, Vergi Bilincinin Topluma Yayılmas1 ve Vergilerle İlgili Son Düzenlemeler", Yaklaşım Dergisi, 5(52), 8-9.

Taytak, M. (2010), “İlköğretim II. Kademe Öğrencilerinde Vergi Bilincinin Tespiti: Ampirik Bir Araştırma", Maliye Dergisi, 158, 496-512.

Torgler, B. (2005), “Tax Morale and Direct Democracy”, Europen Journal of Political Economy, 21, 525-531.

Yakışık, H. (2006), “Kırgızıstan'da Kayıt Dışı Ekonominin Boyutları: Etkileri ve Tahmini”, Doktora Tezi, Kırgızistan - Türkiye MANAS Üniversitesi, Sosyal Bilimler Enstitüsü, İktisat Ana Bilim Dal1.

Yeşilyurt, Ş. (2015), "Vergi Bilincinin Vergi Ahlakı Üzerindeki Etkisi: Maliye ve İlahiyat Bölümü Öğrencileri Örneği”, Mustafa Kemal Üniversitesi Siyasal Bilgiler Fakültesi, Mustafa Kemal Üniversitesi Sosyal Bilimler Enstitüsü Dergisi, 12(32), 36-56.

Zorlu, Ö. (2012), “İlköğretim çağındaki öğrencilerin vergi bilinci düzeyi ve vergi bilinci düzeyi ile ilgili örnek uygulama: Ankara İli Örneği”, Yüksek Lisans Tezi, Gazi Üniversitesi Eğitim Bilimleri Enstitüsü, Ankara. 